New Black Power: Constructive Resilience and the Efforts of African American Bahá'ís

\section{DERIK SMITH}

In 1966, the leader of the Student Nonviolent Coordinating Committee stood in Mississippi and raised a call, "What do we want?" A resounding response poured from hundreds of voices, "Black Power!" (Jeffries 171). This was the first time that the two words came together as a public rallying cry, a punctuating symbol in political struggles in the United States. In the decades after Stokely Carmichael (later known as Kwame Ture) led that chant in Mississippi, the slogan "Black Power" became an activist mantra throughout the Black Diaspora. While the assertion that "Black Lives Matter" has moved to the forefront of the activist lexicon in recent years, the idea of Black Power remains potent. Yet our conceptions of Black Power are often limited. This is because our conceptions of power itself are limited. As the Universal House of Justice suggests, we frequently think of power as a "finite entity which is to be 'seized' and 'jealously guarded"" (2 Mar. 2013). But power can be conceived of in different ways; indeed, the Bahá'í approach to social transformation compels us to expand our conceptions of power-Black Power included. We may need to develop new images of power and Black Power especially, as we learn about how individuals, institutions, and communities can use constructive resilience to transform society and respond to social oppression-especially oppression that emerges from racism, "a profound deviation from the standard of true morality" (Universal House of Justice, 22 July 2020).

The House of Justice has directed our gaze toward a number of examples of constructive resilience. In spite of "relentless oppression," the Bahá'í community of Iran provides a potent model of constructive resilience. It has been "forward-looking, dynamic, vibrant," never submitting to "despair, surrender, resentment, and hate," while seeking to transform Iranian society (2 Mar. 2013). The House of Justice also indicates that "the same expression of constructive resilience" has animated efforts of American Bahá'ís, especially African American Bahá'ís who have labored for more than a century to transform American society by promoting race unity (4 Feb. 2018).

To sustain these efforts in constructive resilience, African American Bahá'ís have summoned a special Black Power - crafted of determined fortitude, patience in the face of hardship, and hard-bitten yet loving commitment. This power is the stuff of Black life that glints through clouds of injustice and oppression. The glimmering of this radical power doesn't look like the conflictual power that 
smothers our social order, locking competing groups in endless contests, locking away resources, and locking up human potential. In their efforts to promote race unity in an American context corroded by racial prejudice, Black Bahá'ís have eschewed conflictual power to call upon "the powers of the human spirit" (2 Mar. 2013). Often, these are subtle, visually quiet powers that can be hard to see, but are deeply transformative. The untrained eye might misperceive this power and its meaning, but in the history of constructive resilience among African American Bahá'ís, we may see images of this new Black Power. To help us perceive the power of the spirit, the House of Justice has offered some direction. It writes, "Associated with power in this sense are words such as 'release,' 'encourage,' 'channel,' 'guide' and 'enable"” (2 Mar. 2013).

\section{RELEASE}

Robert Turner stands out in the photograph that is the earliest documentation of African American constructive resilience in the Bahá'í Faith. His eyes are calm and vigilant, concentrating on the camera focused on the first group of Western pilgrims to the Bahá'í Holy Land. It seems he stands in the photo's flank, upsetting the symmetry of the other seven pilgrims - six women, perfectly arranged around Ibrahim Kheiralla, the central figure in the scene. The picture feels charged with an ambient tension-an energy strange, familiar, pushing Turner away from the group. But in the midst of this ambient energy, Turner exerts a quiet Black Power, standing resilient, beginning to construct the "door through which a whole race would enter the Kingdom" (qtd. in Gregory, "Robert Turner" 28).

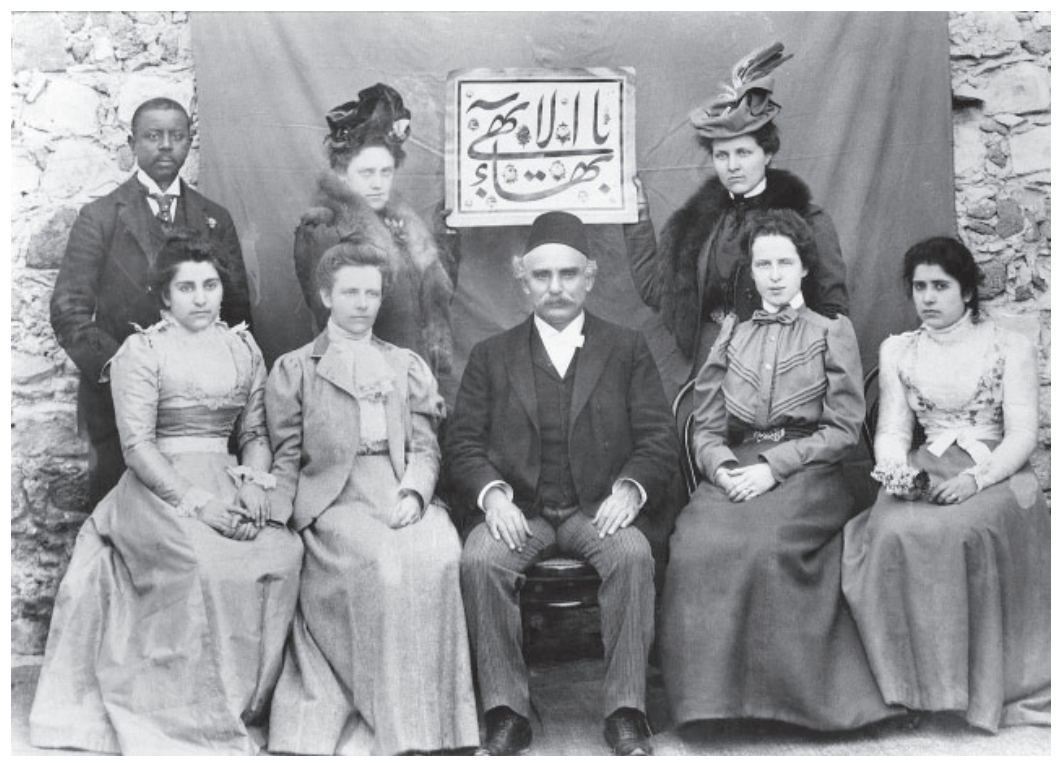

Hearst Pilgrimage, 1898-89

Source: National Bahá'í Archives, United States 
Sources say this is what 'Abdu'l-Bahá told Turner - that if he remained faithful, he would become a portal of entry, channeling, guiding a people toward Bahá'u'lláh.

Not long after the photograph was taken, the man at its center would abandon the Bahá'í Faith. But Turner, the first African American Bahá'í, holding space in the margins of the photograph, would go to his grave holding fast to the faith of Bahá'u'lláh. What thoughts and emotions coursed through Turner in that moment fixed in history by the photo? Perhaps his steady eyes reveal the summoning of resilience that would bear him up as a Black man soldiering through the late-nineteenth century world. But, perhaps, in Turner's gaze we also see his spiritual connection to the strength in the gaze of Lua Getsinger. It was Getsinger (seated second from the right), the tireless promulgator of the Bahá'í Faith, the "Mother of the Believers," who had constructed a spiritual bond with Turner, introducing him to the teachings of Bahá'u'lláh. It is likely that she was the first to tell Turner of the Man they would meet in the Holy Land.

\section{ENCOURAGE}

Both Turner and Getsinger were sustained by 'Abdu'l-Bahá's perfect embodiment of encouragement. His legendary love had drawn the pilgrims to the Mediterranean coasts of Palestine in 1898. Knowing only of His exalted station, Turner was abashed as he anticipated his first meeting with
'Abdu'l-Bahá. He was employed as the butler of one of the other pilgrims, and thought it best to wait outside the gathering place. But sensing his absence, 'Abdu'l-Bahá stepped to the doorway and invited him in. Uttering, "My Lord! My Lord! I am not worthy to be here," Turner fell to his knees, only to be drawn up into the embrace of 'Abdu'l-Bahá, the Center of the Covenant (Gregory, "Robert Turner" 28).

What power was released in that encouraging embrace that drew Turner from the margin to the center? Perhaps Turner remembered that moment as he readied himself for another photograph - one that would later be sent to 'Abdu'l-Bahá. In it, Turner stands alone, his body angled, looking off into our future, perhaps. He smiles with a beauty quiet and irrepressible. Turner, born enslaved, somewhere in Virginia, sometime in the 1850s, channels in his pose a tradition of African American resilience - a tradition born of innumerable acts, gestures, and glances of encouragement, shared between Black people bearing up in the midst of violently oppressive power.

Turner lived in a world that underrated the beauty and power of the tradition that sustained him. Maybe he believed that 'Abdu'l-Bahá-appearing to live in that world - could have forgotten the grace that he brought to the Holy Land in 1898 . When his beaming photograph was sent to 'Abdu'l-Bahá, we can imagine that Turner was gripped by a double-emotion: he surely brimmed with the excited thought that the Mystery of God Himself would 
soon hold his photo; but he must have also been anxious, thinking the photograph might be ignored, and that 'Abdu'l-Bahá might have somehow forgotten him.

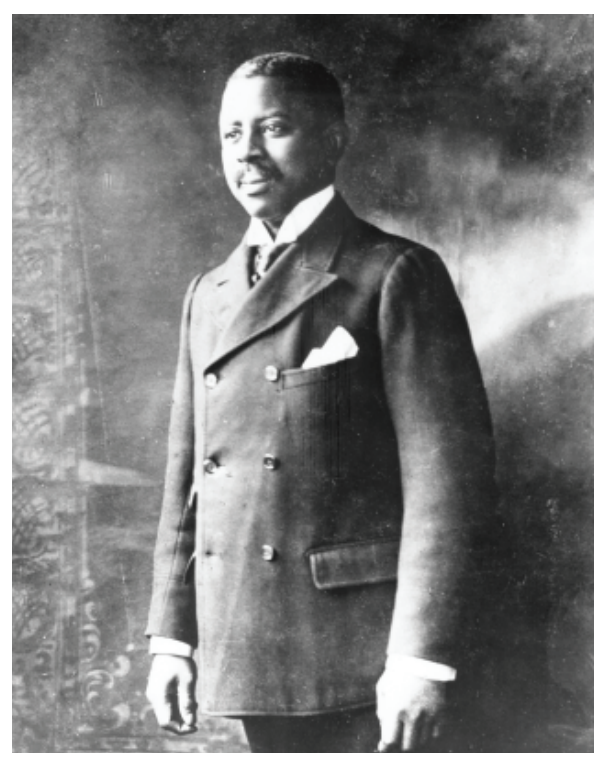

Robert Turner

Source: National Bahá'í Archives,

United States

Imagine, then, the power that must have surged within Robert Turner when he encountered 'Abdu'l-Bahá's response to his photograph. A universe of encouragement was condensed into the tablet:

O thou who art pure in heart, sanctified in spirit, peerless in character, beauteous in face! Thy photograph hath been received revealing thy physical frame in the utmost grace and the best appearance. Thou art dark in countenance and bright in character. Thou art like unto the pupil of the eye which is dark in colour, yet it is the fount of light and the revealer of the contingent world. I have not forgotten nor will I forget thee. (Selections 114)

Turner, himself, would never forget his faith. On his deathbed, he continuously repeated "an expression strange and unknown"; in fact, he was going to his God with the words "Yá Bahá'u'lAbhá" upon his lips (Gregory, "Robert Turner" 29). Shoghi Effendi designated him a Disciple of 'Abdu'l-Bahá posthumously.

Out of slavery, Turner had built himself into the living portal through which a race "will enter the Kingdom." In Turner's grace-filled portrait we see, for the first time in history, the living confluence of two streams of powerone welling from the deep reservoir of African American resilience, and the other gushing from the infinitely creative Revelation of Bahá'u'lláh. As these streams merged in Robert Turner, he became a fountain of light through which a new Black Power flowed into the world.

\section{ChANNEL}

Sadie Oglesby sits calmly in the photo, her gaze inescapable. The transparent lenses of her wire-rimmed glasses amplify the sense of unwavering determination in her eyes. Like Turner, she had visited the Holy Land, and was empowered, transformed. Oglesby was a trained nurse, a champion of the Bahá'í 
Faith, and the first African American woman to undertake a pilgrimage to the Holy Land. In 1927, after spending twenty days in Haifa and 'Akká, she returned to the United States and asserted, "We are not the same people we were before we went away" (qtd. in Etter-Lewis 79). The photograph captures her years after her battery of conversations with Shoghi Effendi. Oglesby's historic pilgrimage was marked by repeated exchanges with the Guardian of the Bahá'í Faith. They followed a pattern: he wanted to know about race and the American Bahá'í community; she would respond earnestly; and he would then emphasize the urgency of

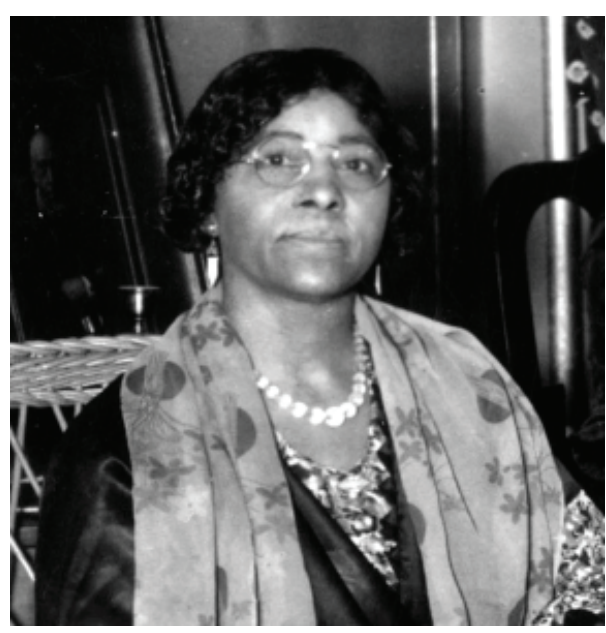

Sadie Oglesby

Source: National Bahá'í Archives, United States

the need for race unity and the infusion of Blackness into the community.

"If we wish The Cause to grow in America, that which is the cause of so few colored believers must be removed." This was the substance of the message that Oglesby heard from the
Guardian. This was the "vital" thing (281).

In her photograph, perhaps we can see the sense of responsibility that Oglesby took on after those transformative conversations - the strength of will necessary for channeling Shoghi Effendi's guidance for the American Bahá'ís. In 1938 Shoghi Effendi would concretize this guidance in The Advent of Divine Justice, calling upon the American Bahá'í community to recognize that racial prejudice was its "most vital and challenging issue." And he would emphasize that this problem was invested "with an urgency and importance that cannot be overestimated" (Advent 34).

Surely, few felt the gravity of these words more viscerally than Oglesby. Shoghi Effendi had personally expressed to her the self-same message that was enshrined in his 1938 letter to the North American Bahá'í community. We imagine that Oglesby had looked into his searching, powerful eyes and resolved to be the channel through which the work of race unity would flow. In Boston newspapers of the 1930s and 1940s we can trace Oglesby's channelling labour. Notes about her talks pepper the historical records of that era- "race amity" is the recurring theme. An attractive force flowed from her. Drawing people-Black people, especially-to the Bahá'í Cause, she constructed a foundation.

In 1935, Hand of the Cause of God Louis Gregory wrote a report about her work: "Many new faces are found 
among the Boston friends, a large proportion of whom are colored. These were reported attracted largely through the spiritual finesse of Mrs. Oglesby" ("Race Amity" 11). The wonderful description of Oglesby's work as "spiritual finesse" suggests the grace of her efforts to channel the unifying message. But it also conceals the sheer labor of her constructive work, helping to build the foundations of a unified interracial community within an American social structure vitiated by what Shoghi Effendi called the "corrosion" of racial prejudice. It is likely that Oglesby endlessly called upon great reservoirs of African American resilience as she labored among those struggling to relinquish "once and for all the fallacious doctrine of racial superiority, with all its attendant evils, confusion, and miseries" (Advent 39). In this welter of miserable, confused evil, Sadie Oglesby-like millions of African American women-sacrificially constructed a foundation upon which others now stand. Constructive, resilient power channels through the gaze that flows from her photo.

\section{GUIDE}

Creadell Haley stands in the photograph, tall beside her airplane. It is 1946, and the Illinois banks of the Mississippi River are nearby. Haley had not yet encountered the Word that Oglesby channeled on the East Coast. But moments before posing for her commemorative portrait, she was guiding an aircraft through the skies above Jim
Crow America, developing powers that she would soon exercise in service of her Faith. The photograph freezes Haley just after her first solo flight. It had been difficult. Blown off course, and running low on fuel, she landed in an oat field and spent the night in a small farm town (Ankrom). But beneath the wing of the single-engine plane, Haley looks undisturbed by whatever difficulties she had encountered in the air. One foot forward, she seems ready for what is next.

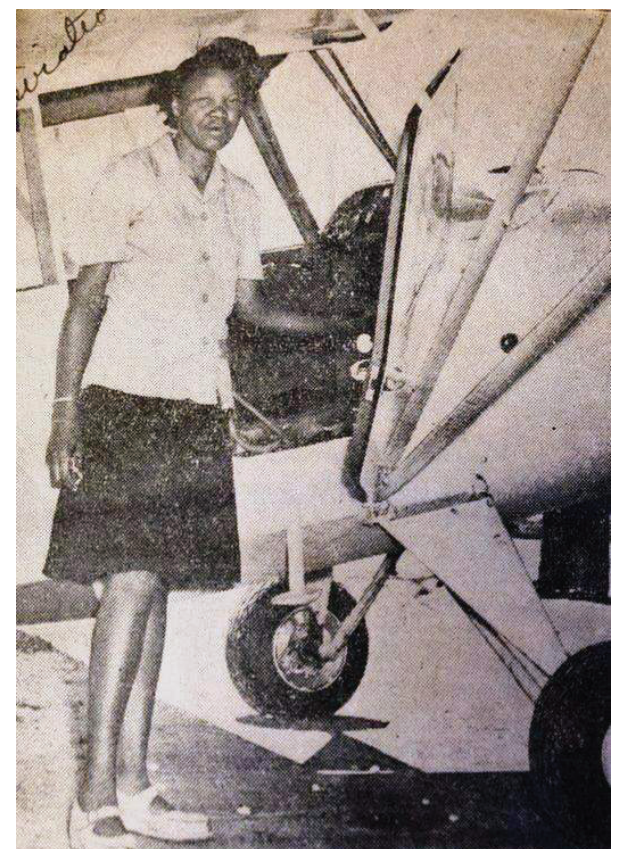

Creadell Haley

Photo courtesy of The Quincy Herald-Whig

The spirit dwelling in the tall figure in the photograph must have already known the secrets of Black women's resilience. She was raised by an aunt and uncle in the white-bread Midwest. During World War II, she was a military mechanic, earning the rank of sergeant in the Women's Army Air 
Corps. Among African Americans of that era, folk wisdom taught that "the army ain't no place for a Black man." What then was the army like for a Black woman? We can only imagine the powers that Haley summoned as she navigated her time in the service. In the photograph we see an American military veteran who had been stationed throughout the country, studying its people and the arts of resilience as she studied engines. Sometime after she posed next to the airplane, Haley would head west, to California, to study music. Here she would encounter the Bahá'í Faith and study again, internalizing its verities, learning to channel the powers of the human spirit that would allow her to pilot others toward strength.

By 1968, Creadell Haley's name was among several dozen published in The National Baha' 'i Review. That year she was one of a small group that left America to help construct nascent Bahá'í communities all over the planet. Haley would offer three decades of service as a pioneer in Venezuela. There was no hyperbole in the note that prefaced the list of pioneers that included Haley: "The entire American Community should be eternally grateful to these 47 courageous and dedicated fellow-believers" ("Time-Clocking" 4). She was among a precious handful sacrificially advancing a global plan directed by the Universal House of Justice. When we look yet again at Haley beside her airplane, and think of her departure for South America, her fearless independence seems still more remarkable. But in pioneering - "the prince of all goodly deeds"-fearless independence is only an apprentice's power; perhaps the lofty station of the pioneer is truly achieved when the power of independence blends into the power of deep connection with others, and the capacity to guide and nurture (Bahá'u'lláh 157:1).

Before leaving the United States, Haley had also demonstrated these connection-forming capacities by binding together the thousands who learned the words and melodies that she composed. As the 1960s roiled through America, twisting its culture into new shapes and shifting the tones of its discourse, Haley conceived a body of music that was deceptively simple and direct, always returning to the ideas captured in the refrains of two of her most well-known songs, "Bahá'u'lláh" and "Love, Love, Love." That was all. These songs were small temples within which groups would harmoniously gather; they became staples in the musical repertoire of Bahá'í communities throughout the world. Hearts were led toward spiritual perception while sheltered within the melodic architecture that Haley constructed around her themes. When she took up her South American pioneering post, Haley left behind her these song-gifts that helped guide the devotional culture of Bahá'í communities.

Haley's musical gifts sound as though they float from a transcendently pure heart. In the airy simplicity of her song "What Mankind Has to Learn," the earnest wish for racial 
union is delivered with the lightest of touch: "There is only one race of man upon the earth. / But man did divide it and so / there's a black race, a white race. / What mankind has to learn is that there's only one race to know." The lilting melody that clothes her lyrics makes it possible to forget that these words address corrosive racial prejudice and the immorality of "the fallacious doctrine of racial superiority" (Shoghi Effendi, Advent 39). Indeed, it seems that Haley had somehow transcended the strife and the struggle of racism even as her lyrics evoke it. But if Haley somehow flew just above the rancor of race, guiding others by her example of transcendence, we cannot forget that transcendence is the afterlight of resilience. The young Black woman photographed beside her airplane, moments after descending from skies above, surely knew all about resilience.

\section{ENABLE}

The group is made up of mostly younger men. Each one channels into the camera his own spirit and power. The 2009 photograph captures one small cadre of the hundreds of men who contributed to the Bahá'í Black Men's Gathering (BMG) during its twenty-five-year history. In 1987, the year of the first BMG, America was descending into its misbegotten "war on drugs"; rates of incarceration for Black men were in precipitous ascent; and violence raged in neighborhoods where millions of African Americans had been sequestered and virtually abandoned by their countrymen. Many decades earlier, but probably not long after He had embraced and encouraged Robert Turner, 'Abdu'l-Bahá warned that only "a revolutionary change in the concept and attitude of the average white American toward his Negro fellow citizen" could avert a fate in which "the streets of American cities [would] run with blood" (qtd. in Shoghi Effendi, Citadel 126). By the 1980s the change had not come, and in American cities streets were absorbing the blood of young Black men. Tens of thousands of us were dying violently each year. This bloodshed provoked a range of responses: the state built prison-cages at an unprecedented clip; the national imagination fortified narratives that vilified Blackness; and the hip-hop generation raised up a defensive counter-culture that tried to "improve society by fighting its evils" (Universal House of Justice, 10 Aug. 2018)—indeed, Public Enemy's "Fight the Power" was one of our anthems. But in the midst of all this, one Bahá'i engaged the moment with an alternative. He began constructing a network of relationships between Black men that would foster the power of resilience and help advance the Cause of God.

Each of the souls in the photograph had, at some time or another, been embraced and encouraged by William "Billy" Roberts, the founder of the BMG. His spirit seemed to channel both the seriousness of Black Power anthems by Public Enemy and the spiritual substance of songs by Creadell 
Haley. He was the father of the Gathering. He understood that Black men possessed individual resilient power, but that the traumas of American life intertwined with "fallacious" racial doctrines rendered that power unrecognizable to most Americans, to many Bahá'í communities, and even to those who possessed it. Described by the Universal House of Justice as a "capable facilitator" (28 Aug. 2011), Roberts also knew that the fusion of individuals into a loving, service-oriented collective would release an unknown power. He knew that a gathering could be much more than the sum of its parts. needed to dissolve the hardness, the aloofness, the furrowed brows that were the protective shields we brought in from battles with a perverse world. It was primarily the moistening power of prayer that dissolved the clay. Rousing, collectivist prayers channeled together the Divine Word and the Black experience of modernity. Voices golden and gravel contributed to praise-songs communally and spontaneously devised in sessions that could stretch for hours. The call-and-response structures of Black worship bound hearts; the drums talked beneath tablets that were recited in numerous languages; power

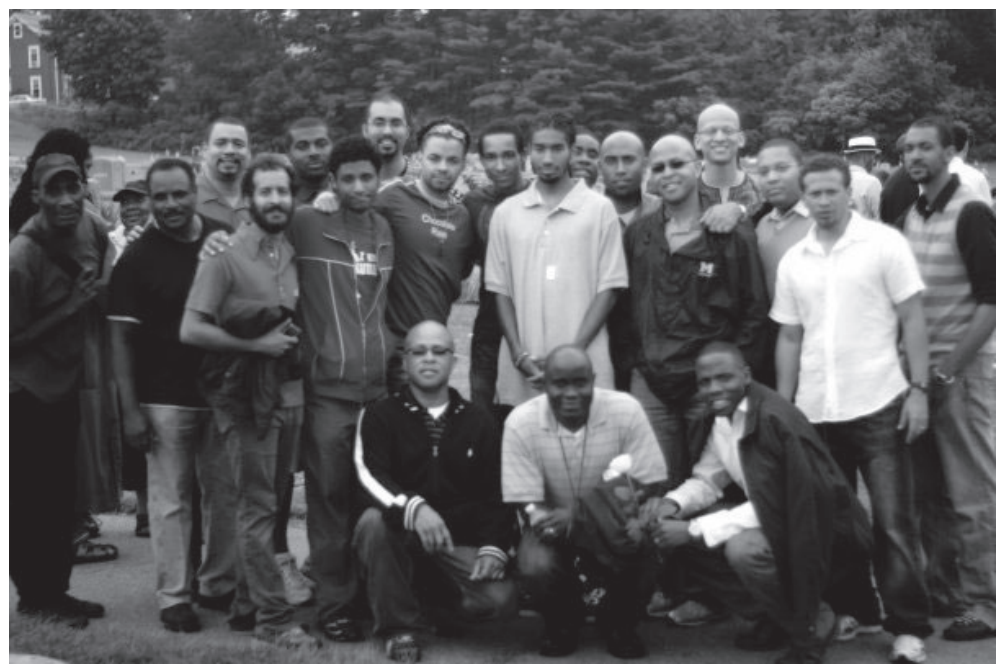

The Black Men's Gathering

Photo courtesy of the author

But creating the conditions that would enable Black men to collectively amplify their powers of resilience and service required spiritual finesse. The slow-healing wounds of history and the encircling dangers of living while Black layered many BMG brothers in the defensive clay of suspicion and posturing. A touch of moisture was was released within and between the gathered men. In the photograph of the brothers, we feel the steady energy that flows between them. The image, slightly unfocused, captures us after long days of prayer.

In the early years of the Gathering, perhaps there was perplexity among Bahá'ís who felt excluded by 
the exceptional assemblage of Black men. Was this arrangement admissible in a Faith that pivoted on belief in the oneness of humanity? What were these men doing in their gathering? What grievances were they sharing? These questions were quieted in two ways, the one connected to the other. Most significantly, the House of Justice, "acknowledging the uncommon circumstances" facing Black men in America, "lent its support" to the Gathering, deeming it a necessary "bulwark" for healing and empowerment (28 Aug. 2011). And in a reciprocal response to the sanctioning protection offered by the Supreme Body of the Bahá'í Faith, the Gathering demonstrated itself a generator of constructive agency. In the diverse collection of figures in the photograph, we see a few of the agents who contributed to the long record of service that unfurled from the Gathering. The style of spiritual communion that grew there was transplanted in dozens of localities, invigorating the devotional culture of the Bahá'í world; travel teachers undertook journeys throughout the African diaspora and elsewhere; pioneers set off to posts on the home front and abroad; and scores of BMG participants began serving on administrative institutions. Grievance had no role in the Gathering; service was the watchword-especially service along those paths illuminated by the encouraging Universal House of Justice.

Many of the figures in the photograph are just slightly off balance. They lean on one another, but perhaps they are also leaning into service. The photo finds us on the last day of the Gathering in 2009-with our hearts open, and our wills steeled, we're preparing for a return to the field, preparing to make good on the personal vows we'd made to carry out the plans of House of Justice, which we pored over, hour after hour. As one of the brothers once said, "There's a pledge, there's a promisenot something you broadcast to everybody-you have this desire to serve and not to squander the unique opportunity you've had to be in that place at that time, and to receive those kinds of blessings, and to go back home and not get into the field of service ... well that would just be a mockery of the Gathering" (Done Made). During those days of fellowship and study, we sought to internalize the marching orders we received in the Plans. In 2011, when the Gathering was addressed by the House of Justice for the last time, we knew that the true upliftment of Black people, and the justice and unity which we longed to experience, remained far off. But we also knew that we had the means to bring on the social and spiritual change we prayed for. Bidding us to "advance" into the field, and "to conquer the hearts," the House of Justice- - "source of all good and freed from all error" ('Abdu'l-Bahá, Will and Testament 14) - left us with a simple but profound statement about enabling Black Power: "The institute process is the primary vehicle by which you can transform and empower your people, indeed all the peoples of your nation" (28 Aug. 2011). 
A final scan of the photograph notes that one of us holds a white rose - an offering to be left at the gravesite of a champion of service, a Black man who was the embodiment of power, whose very life was the expression of constructive resilience, born of love for Bahá'u'lláh. Just behind the assembled brothers is the resting place of Hand of the Cause of God Louis Gregory and his wife Louisa. Led by Roberts, we would process to that holy site on the final day of our gatherings at the Green Acre Bahá'í School. In the early twentieth century, Gregory and his wife, and their comrade Sadie Oglesby, led numerous race amity conventions at Green Acre. Our annual BMGs at the school, and our culminating processions to Gregory's gravesite, were affirmations of our connection to a history and tradition of constructive resilience animated by Black Power.

An appreciation of the images curated here is amplified by several ideas about the power that animates constructive resilience. This power is not specifically Black, of course. At the heart of constructive resilience is the power of the human spirit, which "has no gender, race, ethnicity or class" (Universal House of Justice, 2 Mar. 2013). If we visualize this power as a substance, it is translucent like water, taking on momentarily the color and the shape of the vessel through which it is channeled. It is essential to recognize that this power does not contend or compete with any other power, Black or otherwise. This power is infinite; it can never be accumulated, corralled, or stored up; it can only be released. As it is released and channeled, it unifies and bonds. Perhaps most importantly, when this power filters through the Divine Word, it is transformative.

The terrible facts of modern history have compelled people of African descent to develop cultures that are ingeniously constructive, necessarily resilient, and filled with power that is associated with words like "release," "encourage," "channel," "guide," and "enable." In the context of the United States, we should continually appreciate the constructive and resilient efforts of the African American friends as we learn about systematically developing the knowledge and practices that will help transform society and build up a divine civilization defined by universal love, unity, equity, and justice.

\section{Works Cited}

'Abdu'l-Bahá. Selections from the Writings of 'Abdu'l-Bahá. U.S. Bahá'í Publishing Trust, 1978.

Will and Testament of 'Abdu'l-Bahá. U.S. Bahá'í Publishing Trust, 1990.

Ankrom, Reg. "Pioneering Pilot's Missions Carried Her Skyward." Herald-Whig, 8 Apr. 2018. hsqac.org/pioneering-pilot-s-missions-carried-her-skyward 
Bahá'u'lláh. Gleanings from the Writings of Bahá u'lláh. U.S. Bahá'í Publishing Trust, 1990.

Done Made My Vow to the Lord: The Baha'i Black Men's Gathering 1987-2011. Produced by Nwandi Lawson and Craig Rothman, 2013.

Etter-Lewis, Gwendolyn. "Race, Gender, and Difference: African-American Women and the Struggle for Equality." Lights of the Spirit: Historical Portraits of Black Bahá 'is in North America, edited by Gwen Etter-Lewis and Richard Thomas, U.S. Bahá'í Publishing Trust, 2006, pp. 69-94.

Gregory, Louis G. "Race Amity.” The Bahá'i News, no. 91, Apr. 1935, pp. 10-11.

___ . "Robert Turner, First Black Believer of the United States." World Order, vol. 12, Apr. 1946, pp. 28-29.

Jeffries, Hasan Kwame. "SNCC, Black Power, and Independent Political Party Organizing in Alabama, 1964-1966." The Journal of African American History, vol. 91, no. 2, Spring 2006, pp. 171-93.

Oglesby, Sadie. "Arrival in Haifa, March 11, 1927." Lights of the Spirit: Historical Portraits of Black Bahá' is in North America, edited by Gwen Etter-Lewis and Richard Thomas, U.S. Bahá'í Publishing Trust, 2006, pp. 277-82.

Shoghi Effendi. The Advent of Divine Justice. U.S. Bahá'í Publishing Trust, 1990.

- Citadel of Faith. U.S. Bahá'í Publishing Trust, 1980.

“Time-Clocking Our Foreign Goals." The National Bahá'i Review, no. 4, Apr. 1968, p. 4.

The Universal House of Justice. Letter to the participants of the Black Men's Gathering, 28 Aug. 2011.

___ Letter to the Bahá'ís of Iran, 2 Mar. 2013. universalhouseofjustice.bahai. org/involvement-life-society/20130302_001

_- L Letter to an individual in the United States, 4 Feb. 2018.

—_- Letter to an individual in the United States, 10 Aug. 2018.

. Letter to the Bahá'ís of the United States, 22 July 2020. bahai.org/ library/authoritative-texts/the-universal-house-of-justice/messages/20200722_001/1\#870410252 